07.2

\title{
Характеристики кремниевого лавинного фотодиода для ближнего ИК-диапазона
}

\author{
() П.Н. Аруев, Б.Я. Бер, А.Н. Горохов, В.В. Забродский , Д.Ю. Казанцев, А.В. Николаев, \\ В.В. Филимонов, М.З. Шварц, Е.В. Шерстнёв
}

Физико-технический институт им. А.Ф. Иофффе РАН, Санкт-Петербург, Россия

` E-mail: sildet@mail.ioffe.ru

Поступило в Редакцию 22 апреля 2019г.

В окончательной редакции 22 апреля 2019г.

Принято к публикации 30 апреля 2019г.

\begin{abstract}
Проведено исследование чувствительности (в диапазоне длин волн $400-1150 \mathrm{~nm}$ ), темнового тока и динамических характеристик разработанного кремниевого лавинного фотодиода с активной областью диаметром $1.5 \mathrm{~mm}$. Показано, что разработанный лавинный фотодиод обладает следующей совокупностью характеристик: чувствительность $80-85 \mathrm{~A} / \mathrm{W}$ в диапазоне длин волн $900-1010 \mathrm{~nm}$, темновой ток $1.5 \mathrm{nA}$, фронты нарастания и спада менее $2.5 \mathrm{~ns}$ при напряжении обратного смещения $350 \mathrm{~V}$.
\end{abstract}

Ключевые слова: лавинный фотодиод, инфракрасный диапазон, кремний, темновой ток.

DOI: 10.21883/PJTF.2019.15.48086.17851

Высокоточная регистрация слабых сигналов видимого и ближнего инфракрасного (ИК) диапазонов, исследования динамики изменения интенсивности световых процессов с характерными (порядка единиц наносекунд) временами являются крайне востребованной практической задачей как для научных экспериментов, так и для промышленного приборостроения. Например, для диагностики плазмы методом томсоновского рассеяния [1] необходимы фотодиоды с внутренним усилением. Кремниевые лавинные фотодиоды (APD — avalanche photodiode) с внутренним умножением носителей заряда за счет эффекта ударной ионизации [2-4] применяются в тех случаях, когда чувствительность системы pin-диод-предусилитель становится недостаточной.

На данный момент в России не существует отечественных коммерчески доступных кремниевых APD с чувствительностью в десятки $\mathrm{A} / \mathrm{W}$ для регистрации оптического диапазона. Цель настоящей работы - исследовать спектральные характеристики разработанного в ФТИ им. А.Ф. Иоффе кремниевого APD в диапазоне длин волн 400-1150 nm при рабочем напряжении $350 \mathrm{~V}$, темнового тока, фронтов нарастания и спада на длине волны $\lambda=1060 \mathrm{~nm}$.

B рамках кремниевой планарной CVD-технологии (CVD - chemical vapour deposition) был разработан и изготовлен APD с активной областью диаметром $1.5 \mathrm{~mm}$, оптимизированный для регистрации сигналов ИК-диапазона с фронтами нарастания и спада меньше 3 ns. Структура разработанного „reach-through“ APD относится к типу „front-illuminated““ (разделение носителей происходит со стороны облучаемой фотоприемной области структуры, рис. 1).

Измерения характеристик приборов проводились в лабораторных условиях при температуре $20-25^{\circ} \mathrm{C}$. Спектральная зависимость фоточувствительности APD ис- следовалась в диапазоне длин волн 400-1150 nm методом сравнения токовых сигналов APD и рабочего этало-
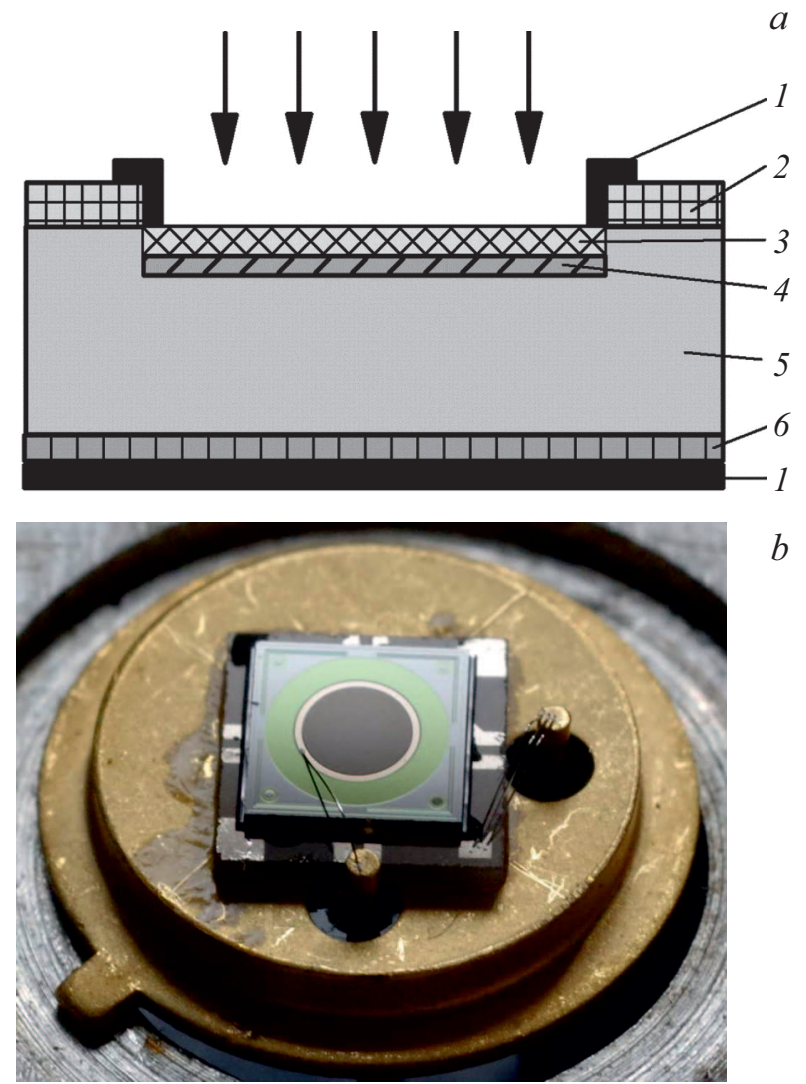

Рис. 1. $a-$ структура APD. $1-$ металлический контакт, 2 - диоксид кремния, $3-n^{++}$-слой кремния толщиной $<1 \mu \mathrm{m}, 4$ - область лавинного умножения $p$-типа (КДБ10), 5 - база, кремний $p$-типа толщиной $\sim 100 \mu \mathrm{m}$ (КДБ5000), $6-p^{++}$-слой кремния толщиной $\sim 0.1 \mu \mathrm{m} . b-$ фотография APD в корпусе TO-5. 

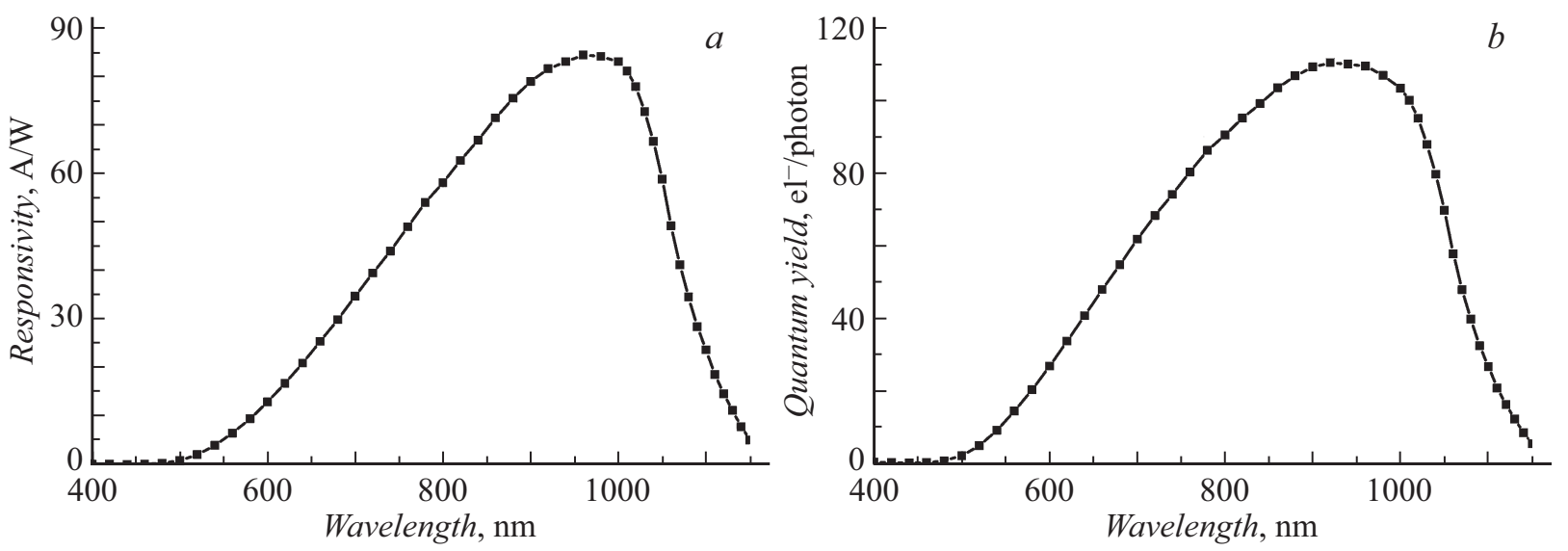

Рис. 2. Спектральные зависимости APD. $a$ - чувствительность, $b$ - квантовый выход фотоответа.
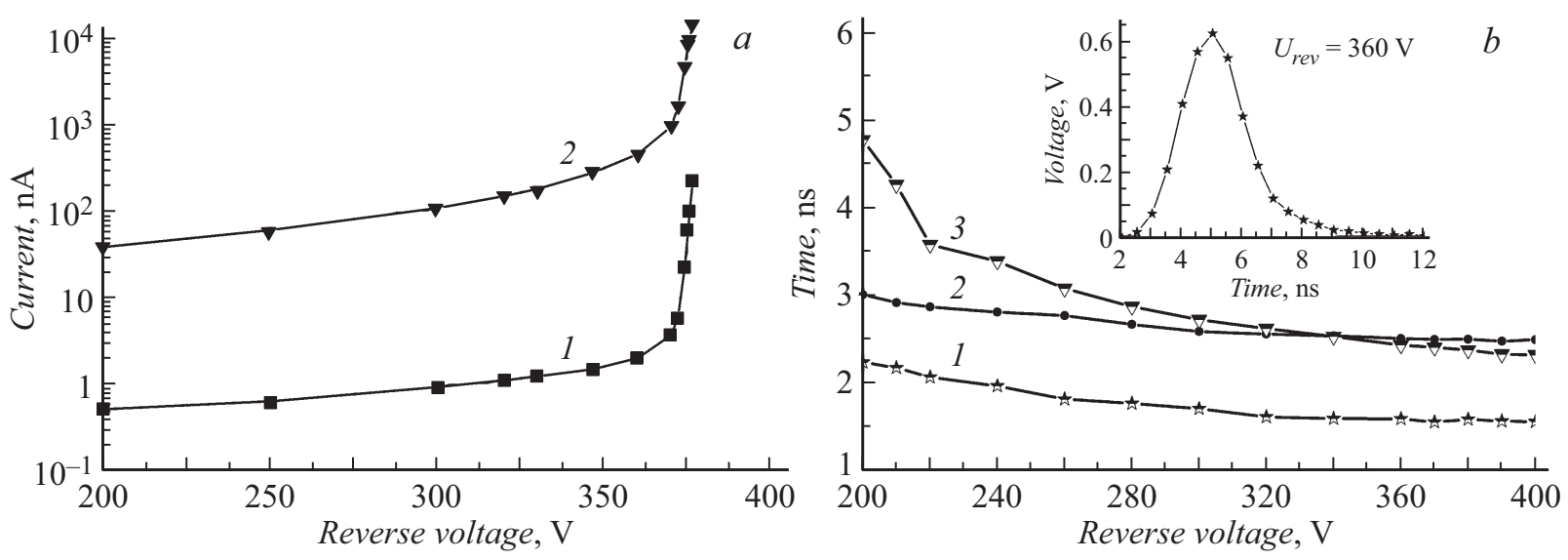

Рис. 3. $a$ - зависимости темнового тока (1) и фототока (2) от обратного напряжения; $b$ - зависимости фронтов нарастания $(1)$, спада (2) и ширины импульса (3) на полувысоте от обратного напряжения.

на (калиброванный кремниевый фотодиод ФДУК-100УТ) с использованием квазистатических пикоамперметров Keithley 6487. Обратное напряжение для исследуемого APD обеспечивалось от встроенного блока питания (на эталонный фотодиод обратного смещения не подавалось).

Абсолютные значения спектральной чувствительности $[\mathrm{A} / \mathrm{W}] \mathrm{APD}$ определялись экспериментально в соответствии с выражением

$$
S(\lambda)_{\mathrm{APD}}=S(\lambda)_{\mathrm{PD}}\left(I(\lambda)_{\mathrm{APD}} / I(\lambda)_{\mathrm{PD}}\right)
$$

где $\lambda$ - длина волны, $I(\lambda)_{\mathrm{APD}}-$ фототок $\mathrm{APD}, I(\lambda)_{\mathrm{PD}}-$ фототок калиброванного фотодиода, $S(\lambda)_{\mathrm{PD}}-$ абсолютная чувствительность калиброванного кремниевого фотодиода, $S(\lambda)_{\mathrm{APD}}$ - измеренная абсолютная чувствительность APD. Значения квантового выхода фотоответа $E Q Y(\lambda)_{\mathrm{APD}}\left[\mathrm{el}^{-} /\right.$photon $]$вычислялись по формуле

$$
E Q Y(\lambda)_{\mathrm{APD}}=\left(S(\lambda)_{\mathrm{APD}} h c\right) /(\lambda q)
$$

где $h-$ постоянная Планка, $c-$ скорость света, $q-$ заряд электрона.
Спектральные зависимости чувствительности и квантового выхода фотоответа APD при напряжении обратного смещения $350 \mathrm{~V}$ представлены на рис. 2.

Для исследования обратной ветви вольт-амперной характеристики использовался пикоамперметр Keithley 6487 со встроенным блоком питания. Зависимости от обратного напряжения темнового тока и фототока (на длине волны $1060 \mathrm{~nm}$ ) APD в диапазоне напряжений 200-380 V представлены на рис. 3, a. Зависимости динамических характеристик APD от обратного напряжения строились на основе данных, получаемых с помощью цифрового осциллографа (с полосой пропускания $500 \mathrm{MHz}$ ), лазерного диода (длина волны $1060 \mathrm{~nm}$ ), генератора испытательных импульсов И1-14, блока питания пикоамперметра, трансимпедансного усилителя с коэффициентом усиления $680 \mathrm{~V} / \mathrm{A} \mathrm{и} \mathrm{полосой} \mathrm{пропус-}$ кания $\sim 400 \mathrm{MHz}$. Зависимости фронтов нарастания и спада, а также ширины импульса на полувысоте от обратного напряжения представлены на рис. 3, $b$. Пример осциллограммы фотоотклика APD (подключенного к трансимпедансному усилителю) на импульс лазерного диода представлен на вставке к рис. $3, b$. 
Оценка коэффициента умножения APD не является тривиальной экспериментальной задачей, так как формально для этого необходимо знать абсолютное значение фототока APD при коэффициенте усиления ( $M$ - multiplication), равном единице, что проблематично в силу конструктивной особенности структуры APD. Данная особенность обусловлена наличием градиента концентрации бора между слоем умножения $\left(10^{15} \mathrm{~cm}^{-3}\right)$ и слоем базы $\left(10^{12} \mathrm{~cm}^{-3}\right)$. В свою очередь градиент концентрации бора формирует встроенное поле изотипного перехода, которое блокирует движение фотоиндуцированных электронов из базы в направлении $n-p$-перехода через слой умножения. Если регистрировать фототок APD без подачи обратного смещения (именно в этом случае $M=1$ ) в ближнем ИК-диапазоне, то измерения будут некорректны, так как вклад в фототок фотоиндуцированных электронов из базы будет близок к нулю. Сбор же неосновных носителей заряда, индуцированных ближним ИК-спектром, будет происходить только из области умножения (электроны) и из поверхностного $n^{+}$-слоя (дырки). По мере увеличения обратного смещения влияние встроенного поля между зоной умножения и базой на движение электронов будет уменьшаться вплоть до полного устранения, что выразится в виде скачкообразного увеличения фототока при освещении ближним ИК-спектром. Последнее может привести к завышению оцениваемого значения $M$ для APD. Здесь рост фототока может быть ошибочно связан повышением $M$, а не с добавкой из базы носителей, ранее блокированных встроенным полем между зоной умножения и базой.

Однако при увеличении напряжения обратного смещения параллельно процессу снятия влияния встроенного поля между зоной умножения и базой будет неизбежно происходить увеличение реального значения $M$ за счет роста напряженности поля в области $n$-p-перехода. Увеличение значения $M$ для $n$-p-перехода в данной ситуации трудно оценить экспериментально. Это обусловлено тем, что величина фототока (после обеспечения режима сбора носителей со всей базы APD) будет ошибочно присвоена режиму APD с $M=1$. На самом деле в режиме сбора носителей со всей базы APD значение $M$ для $n-p$-перехода уже может быть значительно больше единицы. Это в свою очередь приведет к заниженной оценке $M$ для APD в режиме рабочих напряжений. К диапазону рабочих напряжений будем относить значения, при которых ширина импульса на полувысоте (рис. $3, b$ ) слабо меняется в зависимости от напряжения обратного смещения. В настоящей работе это напряжение находится в диапазоне 220-400 V.

Абсолютные спектральные измерения в ИК-области позволяют провести оценку значения $M$ для APD с достаточной степенью достоверности, так как в ИК-области отсутствует эффект ударной ионизации горячих электронов, характерный для УФ-спектра [5]. Из значений квантового выхода исследованного APD (рис. $2, b)$ следует, что максимальное значение $M=110$ для $\lambda=920 \mathrm{~nm}$ достигается при напряжении обратного смещения $350 \mathrm{~V}$. Следует отметить, что указанная максимальная величина наблюдается для структуры APD, которая не содержит в себе антиотражающего покрытия. Отражение от кремния в области $\lambda=920 \mathrm{~nm}$ составляет величину $\sim 30 \%$. Исходя из этого можно сделать вывод, что значение $M$ для $n$-p-перехода (а не для APD) занижено в 1.3 раза относительно вычисленного $M$ для APD. В данном рассуждении мы не учитываем незначительные потери фотоиндуцированных носителей в поверхностном $n^{+}$-слое толщиной меньше $1 \mu \mathrm{m}$, так как глубина поглощения для длины волны $\lambda=920 \mathrm{~nm}$ в кремнии больше $40 \mu \mathrm{m}[6]$.

Таким образом, в работе представлены результаты исследования чувствительности, темнового тока и динамических характеристик кремниевого APD с активной областью диаметром $1.5 \mathrm{~mm}$, оптимизированного для ближнего ИК-спектра. Показано, что APD обладает совокупностью следующих характеристик: фоточувствительность $80-85 \mathrm{~A} / \mathrm{W}$ в диапазоне длин волн 900-1010 nm, темновой ток $1.5 \mathrm{nA}$, фронты нарастания и спада менее $2.5 \mathrm{~ns}(\lambda=1060 \mathrm{~nm})$ при напряжении обратного смещения $350 \mathrm{~V}$.

\section{Благодарности}

Авторы благодарны коллегам из ФТИ им. А.Ф. Иоффе: Н.В. Забродской, М.С. Лазеевой, М.В. Дроздовой, В.И. Маршаловой за помощь в изготовлении фотодиодов и М.Е. Левинштейну за полезное обсуждение результатов работы.

В проведенных исследованиях использовалось оборудование ЦКП „Материаловедение и диагностика в передовых технологиях“ (ФТИ им. А.Ф. Иоффе), поддерживаемого Минобрнауки.

\section{Конфликт интересов}

Авторы заявляют, что у них нет конфликта интересов.

\section{Список литературы}

[1] Забродский В.В., Калинина Д.В., Мухин Е.Е., Раздобарин Г.Т., Суханов В.Л., Толстяков С.Ю., Тукачинский А.С. // ЖТФ. 2003. Т. 73. В. 8. С. 118-122.

[2] Chynoweth A.G. // Semiconductors and Semimetals. V. 4. N.Y.: Academic Press, 1968. Ch. 4. P. 263-325.

[3] Кузьмин В.А., Крюкова Н.Н., Кюрегян А.С., Мнацаканов Т.Т., Шуман В.Б. // ФТП. 1975. Т. 9. В. 4. С. 735-739.

[4] Lee C.A., Logan R.A., Batdorf R.L., Kleimack J.J., Wiegmann $W$. // Phys. Rev. 1964. V. 134. N 3A. P. A761-A773.

[5] Kolodinski S., Werner J.H., Wittchen T., Queisser H.J. // Appl. Phys. Lett. 1993. V. 63. N 17. P. 2405-2407.

[6] Handbooks of optical constants of solids / Ed. E.D. Palik. San Diego: Academic Press, 1998. 999 p. 